\title{
TV DIGITAL: Uma Ferramenta para a Educação
}

\author{
Manoel C. de Amorim Neto ${ }^{1}$, Ivaldir H. de Farias Junior ${ }^{2}$, Fernando da C. Andrade Neto ${ }^{3}$ \\ ${ }^{1}$ Universidade Federal de Pernambuco (UFPE) - Recife - PE - Brasil \\ ${ }^{2}$ Faculdade do Vale do Ipojuca (FAVIP) - Caruaru - PE - Brasil \\ ${ }^{3}$ Partec Participação e Consultoria Ltda - Recife - PE - Brasil \\ mcan@cin.ufpe.br, ivaldirjr@favip.edu.br, fernando@partecweb.com.br
}

\begin{abstract}
The distribution system of television signals in Brazil is already in process of transition where the analog and digital technologies are being transmitted in parallel. One of the most important goals of the deployment of Digital TV in the country is the possibility of social inclusion for millions of Brazilians through access to digital technology. This article analyzes the situation of the Digital TV, demonstrating details of its technology, presenting possibilities and revealing one of the most important applications that it has to offer, which is in the educational context.
\end{abstract}

Resumo. O sistema de difusão de sinais de televisão no Brasil, teve em dezembro de 2008 o início de um processo de transição da TV analógica para a Digital, onde as transmissões analógicas e digitais estão sendo transmitidas paralelamente. Um dos mais importantes benefícios e objetivos desta implantação é a grande possibilidade da inclusão Social de milhões de brasileiros por meio da tecnologia digital. Diante deste cenário, este artigo tem como principal objetivo, fazer uma análise sobre a situação da TV Digital apresentando detalhes de sua tecnologia e abordando uma das possíveis e mais importantes aplicações que é a sua utilização no contexto educativo.

\section{INTRODUÇÃO}

A televisão é o principal meio de comunicação de massa, sendo inqüiestionavelmente uma grande fonte de informação, entretenimento e indução ao consumo da maior parte das populações de países em todo o mundo. A supremacia do aparato se consolidou gradativamente desde o seu surgimento, em meados do século $\mathrm{XX}$, mas principalmente após o rápido desenvolvimento tecnológico que possibilitou a portabilidade dos equipamentos, as produções de programas de televisão diferenciados que fogem da rotina dos estúdios e próxima à verdade explícita das ruas, ou ainda a invenção do vídeo - tape e a disseminação das locadoras de filmes por volta de 1980, a explosão do uso dos videocassetes que rapidamente se configurariam no aparelho que sinalizou para uma futura segmentação dos conteúdos, possibilitada em seguida pelas novas tecnologias.

A principal característica da televisão convencional, analógica, diz respeito à maneira como o conteúdo é difundido. Normalmente, um conteúdo televisivo é criado para atender a um público-alvo bastante diverso, tendo com isso um grande leque de abrangência, embora a segmentação já seja possível em sistemas mais avançados de transmissão, em sua história essa possibilidade foi sempre muito restrita. 
Os dados, antes expostos analogicamente, na forma de vídeo, áudio, gráfico e texto poderão utilizar a futura plataforma de TV digital para serem acessados, baixados, armazenados e vistos mais tarde, de forma que a TV possa ser um meio rico de acesso à informação propiciando uma inclusão digital para as camadas mais carentes da nossa sociedade, tendo em vista que $89 \%$ dos lares brasileiros têm uma TV. O computador em rede, por sua vez, permite um alto grau de personalização de acordo com as características do usuário e uma segurança cada vez mais eficiente do conteúdo acessado por meio da recuperação de informações específicas conforme o seu interesse. Os sistemas computacionais e a comunicação pela Internet podem organizar e disponibilizar para o usuário dados absolutamente individualizados, conforme hábitos de navegação registrados pelos marcadores de acesso ou outros dispositivos técnicos, por meio do protocolo IP.

Uma discussão que acompanha a evolução tecnológica dos dois equipamentos, dos aparelhos de televisão e dos computadores, está relacionada com a utilização desses aparatos tecnológicos no contexto educativo pelas sociedades que incorporam seus recursos, como um instrumento de ensino. O presente trabalho pretende acoplar a essa discussão, já em andamento sobre o uso dos computadores nos procedimentos pedagógicos, uma possibilidade de apropriação e uso efetivo e crítico da televisão digital nos processos de disseminação, aquisição e construção do conhecimento.

\section{TECNOLOGIA DA TV DIGITAL}

"A TV Digital não é apenas uma evolução tecnológica da TV analógica, mas uma nova plataforma de comunicação, cujos impactos na sociedade ainda não estão completamente claros", diz o documento elaborado pelo CPqD (Centro de Pesquisa e Desenvolvimento em Telecomunicações) e pelo Genius Instituto de Tecnologia. [13] É um sistema de televisão composto por transmissão, recepção e processamento digital, podendo os programas serem exibidos ao usuário final por meio de equipamentos totalmente digitais ou através de aparelhos analógicos acoplados a unidades conversoras URD - Unidade Receptora Decodificadora, é também conhecida pelos termos IRD - Integrated Receiver Decoder e Set Top Box - STB.

Um sistema completo de televisão pode ser composto por três grupos específicos de trabalho. O primeiro é coloquialmente chamado de "estúdio", que envolve as atividades de produção (gravação das cenas), o segundo componente pode ser classificado como a transmissão dessas informações para o usuário final (telespectador), mais conhecida como "processo de radiodifusão" (broadcast), atualmente realizada de forma analógica e o terceiro grupo chamado de recepção (antena e acessórios/televisor), trata-se do componente que completa o elo necessário para que o telespectador possa desfrutar da programação transmitida pela emissora.

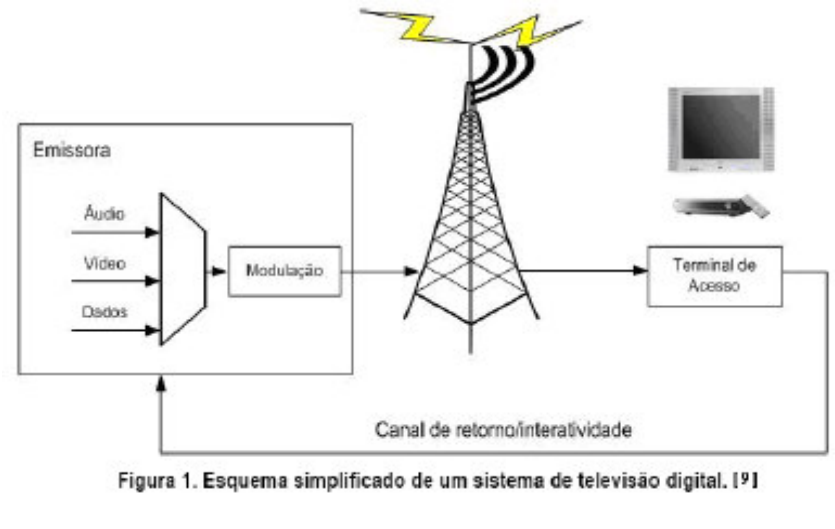


Podemos redefinir Televisão Digital como sendo a transmissão de sinais de televisão na forma digital, e que logo se tem a percepção de excelentes resultados de imagem e um som de melhor qualidade para o usuário. Podendo ainda ter outras vantagens adicionais como, por exemplo, uma imagem mais larga (widescreen), maior grau de resolução, um som etéreo mais envolvente (surround) e a possibilidade de existência de um sistema de múltiplos programas, no entanto, a TV digital vai além da qualidade de alta resolução de imagem e nitidez do som, pois o usuário terá a oportunidade de interagir, assim como faz com a Internet, com a diferença de que terá em um único suporte o acesso à programação de TV e aos serviços da grande rede. Abrindo assim um grande leque de possibilidades. Além das vantagens citadas decorrentes da digitalização dos sinais de áudio de vídeo, podemos desfrutar de outras características funcionais bastante interessantes, a exemplo, melhor tratamento do áudio que propicia reforços nos graves e agudos; maior robustez frente à interferência viabilizando recepção com menores valores de intensidade de campo; maior fluxo de informações fazendo uso da mesma faixa de frequiência; flexibilidade na manipulação e enriquecimento do tratamento e edição de sinais. Esse tipo de procedimento afeta acima de tudo a sociedade como um todo, pois garante maior acessibilidade devido a grandes facilidades para gravações de programas, através do uso de tecnologias de gravadores digitais incluídos nos receptores ou conversores. Reforçando assim a idéia de convergência digital.

\subsection{Arquitetura do Sistema de TV Digital}

Como no modelo OSI1para Redes de Computadores, a arquitetura de um sistema de TV digital é dividida em camadas. Estas têm uma autonomia e prestam ou recebem serviço de suas camadas vizinhas. Esta independência traz flexibilidade para os usuários deste sistema. Cada camada existente possui um grupo de padrões industriais ou de mercado, muitos já implantados.

\begin{tabular}{|c|c|c|}
\hline Subsistema & $\begin{array}{c}\text { Funçāo no ambiente das } \\
\text { emissoras }\end{array}$ & $\begin{array}{c}\text { Funcão no ambiente dos } \\
\text { usuários }\end{array}$ \\
\hline $\begin{array}{c}\text { Transmissão - } \\
\text { Recep̧̧ão }\end{array}$ & $\begin{array}{c}\text { Transmissão do sinal de } \\
\text { TV digital }\end{array}$ & Sintonia do sinal de TV \\
\hline $\begin{array}{l}\text { Modulaç̃̃oe } \\
\text { Demodulação }\end{array}$ & $\begin{array}{l}\text { Adequação (modulação) vo } \\
\text { meio de transmissão }\end{array}$ & $\begin{array}{l}\text { Demodulaçáo do sinal } \\
\text { em fluxo de transporte } \\
\text { codificado }\end{array}$ \\
\hline $\begin{array}{l}\text { Codificạ̧ăo e } \\
\text { Decodificação }\end{array}$ & $\begin{array}{l}\text { Codificaçăo do fluxo de } \\
\text { transporte }\end{array}$ & $\begin{array}{l}\text { Decodificaçāo do fluxo } \\
\text { de transporte codificado }\end{array}$ \\
\hline Transporte & $\begin{array}{l}\text { Multiplexação de vários } \\
\text { programas em fluxo de } \\
\text { transporte }\end{array}$ & $\begin{array}{c}\text { Demultiplexaçăo do } \\
\text { programo selecionado } \\
\text { pelo usuário do fluxo de } \\
\text { transporte }\end{array}$ \\
\hline
\end{tabular}

A arquitetura de TV Digital introduz um conceito de abstração de elementos atômicos do sistema. Áudio, Vídeo e Dados são agrupados em um elemento único chamado de "Serviço". O "Serviço" também é chamado de principal unidade de produção. O início e fim de cada mídia está na semântica do serviço. A união de vários serviços formam um "Bouquet". Os pacotes de TV são administrados com este nível de abstração (vide figura 2).

\subsection{Middleware}

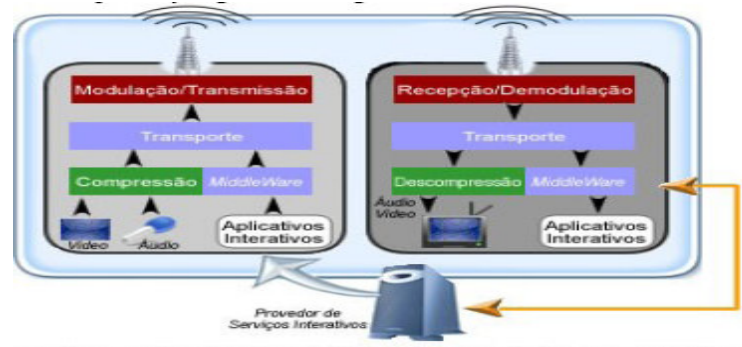


Middleware é um termo geral, normalmente utilizado para um tipo de código de software que atua como um aglutinador, ou mediador, entre dois programas existentes e independentes. Sua função é trazer independência das aplicações com o sistema de transmissão. Permite que vários códigos de aplicações funcionem com diferentes equipamentos de recepção (IRDs). Através da criação de uma máquina virtual no receptor, os códigos das aplicações são copilados no formato adequado para cada sistema operacional. Resumidamente, podemos dizer que o middleware possibilita o funcionamento de um código para diferentes tipos de plataformas de recepção (IRDs) ou vice-versa[4]. O Middleware se faz necessário para resolver o novo paradigma que foi introduzido com a TV Digital: a combinação da TV tradicional (broadcast) com a interatividade, textos e gráficos. Esta interatividade necessitará de várias características e funcionalidades, encontradas no ambiente WEB: representação gráfica; identificação do usuário; navegação e utilização amigável etc.

\subsection{IPTV}

A convergência digital vem se tornando uma realidade cada vez mais presente no dia-a-dia, a integração entre sistemas web e dispositivos móveis já pode ser verificada em algumas aplicações específicas. Com o advento da IPTV surge um novo tipo de dispositivo para ampliar as possibilidades de acesso a informações a qualquer hora, em qualquer lugar. A TVIP ou IPTV é um novo método de transmissão de sinais televisivo que usa o protocolo IP Internet Protocol como meio de transporte do conteúdo. O fato do IP significar Internet Protocol não quer dizer que os conteúdos de televisão sejam distribuídos via streaming na internet. Não é, portanto, uma Web TV.

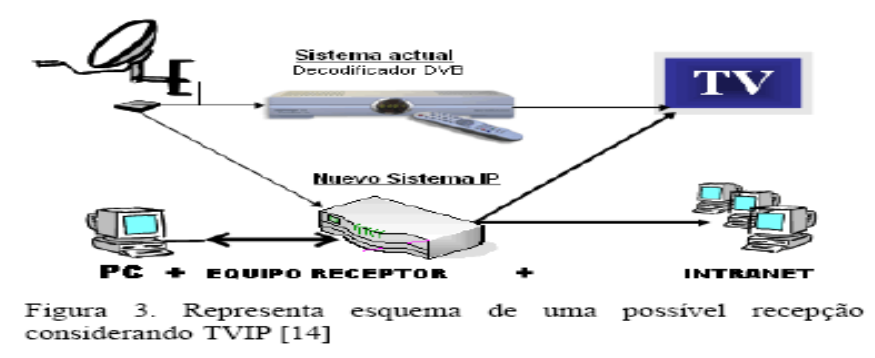

No modelo convencional todos os canais são enviados para o consumidor, estando presentes à entrada do receptor. No IPTV os canais são disponibilizados de acordo com o pedido do usuário.

Em situações mais favoráveis de compressão estarão presentes dois canais, o que permite a visualização de um e a gravação de outro, limitando-se apenas a banda disponível do usuário. O IPTV opera de forma diferente dos sistemas tradicionais de televisão (cabo, satélite e terrestre), dado que apenas os programas previamente selecionados e os conteúdos "on- Demand" são distribuídos ao consumidor. Logo, através dessa nova tecnologia, será possível dispor sempre de duas vias de comunicação, oferecendo uma verdadeira interatividade entre o utilizador e o sistema. É a oportunidade das operadoras de telecomunicação de definitivamente se tornarem Triple Players, ou seja, provedoras de telefonia, internet e televisão, assim como já são muitas das Operadoras de TV a cabo no país. 


\subsection{TV Digital Interativa e a Educação}

TV Interativa é a fusão da TV tradicional, isto é passiva, com tecnologias de computação, processo que permite o telespectador interferir, ou seja, interagir com o que ele está vendo. No modelo tradicional os únicos tipos de interações possíveis eram: mudar de canal, mudar o volume e ligar e desligar. Com a TV Interativa, também chamada de ITV, o telespectador pode interagir para mudar não só o sinal de TV que está recebendo, mas também interferir diretamente na programação da mesma possibilitando a escolha de câmeras em um jogo de futebol, ofertas com serviços de vídeo sob demanda, ou até mesmo participando de votações, de jogos de auditório, e até mesmo escolhendo suas preferências em aplicativos interativos como previsão de tempo, bolsas de valores, notícias de última hora e assim por diante. Desta forma, o intuito é utilizar amplamente o conceito de interatividade, com o propósito de possibilitar altos índices de satisfação de modo que a relação usuário-televisão seja proveitosa, permitindo uma efetiva utilização de todos os recursos e funcionalidades do sistema interativo proposto. Dentre os modelos de categorização de aplicações, os mais utilizados são aqueles que levam em conta aspectos de interatividade, como também será visto mais adiante, na categorização proposta.

Pode-se afirmar que a TV digital interativa é fruto da integração do sistema clássico da TV com o mundo da informática, onde a internet possibilita a interação e a navegação, princípios básicos dessa nova tecnologia que aponta como um grande marco da inovação na área de educação à distância. A utilidade da TV digital interativa no setor de educação se corrobora quando os usuários, professores e alunos, têm a oportunidade de criar e desenvolver seus próprios conteúdos. A idéia requer, portanto, não apenas decifrar a linguagem da comunicação, mas também se servi dela. Incorporando esta experiência, alunos e professores podem perceber significativamente a construção da realidade que todo conteúdo mediático comporta. Esta faceta expressiva é fundamental para conseguir o objetivo de uma educação com os meios.

A TV digital abre as portas, de uma maneira muito especial, para a alfabetização audiovisual permanente, possibilitando e fomentando nos espectadores a capacidade de produzir e analisar suas próprias mensagens. Utilizando a TV desta forma, estaremos propiciando uma educação que promova uma intervenção social e coletiva crítica imprescindível para uma formação de cidadania. A televisão na sociedade capitalista, segundo os teóricos críticos da escola de Frankfurt, é vista como um agente socializador e formador de opinião. O homem, no modelo tradicional de comunicação (emissormensagem-receptor), torna-se objeto e a sua finalidade última é o consumo. A introdução da interatividade na TV coloca em crise este modelo, já que o receptor não será mais um receptor passivo, e sim um receptor ativo.

Admitir tal realidade encaminha-nos para o futuro do uso didático da TV na escola. A interatividade, característica dos novos meios, adquire um sentido pleno no terreno educativo.

\section{CARACTERIZAÇÃO DO PROBLEMA}

O Brasil tem obtido relativo sucesso no desafio de universalizar o acesso à educação. Em 2005, 97,4\% da população entre 7 e 14 anos freqüentava algum estabelecimento de ensino, segundo dados do IBGE [11]. O novo desafio que se coloca ao país é garantir a qualidade 
da educação. Para atingir esse objetivo, uma questão a ser abordada é a motivação dos alunos e professores pela busca do conhecimento extra-sala de aula para agregar valor a sua formação. Essa tarefa tem sido dificultada pelo surgimento de crises na área educacional em diversas regiões. $\mathrm{O}$ aumento da quantidade de alunos sem um equivalente aumento na formação de professores, agravado pela pouca atratividade do material didático utilizado, potencializou os problemas que existem nas escolas e a dificuldade de aprendizagem dos alunos.

Esses fatores levam à indesejável ociosidade dos estudantes nas atividades extra-classe. Nesse contexto, a utilização de tecnologias inovadoras de informação e comunicação pode ser um valioso estímulo para o aprendizado, sendo assim um artifício para incentivar a próatividade dos alunos na busca pelo conhecimento. O mecanismo de ensino, tem seu foco voltado para a área de educação e capacitação das pessoas que dispõem de acesso a dispositivos de convergência digital fixa e móvel como é o caso do computador (internet), celular e TV DIGITAL Embora este público, principalmente no que se trata de TV DIGITAL ( IPTV ) ainda seja restrito, estes dispositivos tecnológicos já são uma realidade e na Europa já são vislumbradas oportunidades de negócios. Grandes empresas já vêm adotando a IPTV como uma própria estratégia de negócio, devido a todas as suas facilidades que garantem um maior contato entre o empregado e o empregador, entre a empresa e seus clientes ou fornecedores, etc. Esse é mais um motivo que o mercado aponta como tendência, apenas confirmando que a IPTV veio para ficar.

De fato a TV Digital é um aparelho em tese mais simples de se operar do que o microcomputador e mais abrangente, hoje em dia, pois mais pessoas o utilizam, no entanto, a tendência é de que essa questão se inverta. Levando em consideração este ponto e de acordo com a agenda estabelecida pela ANATEL (Agência Nacional de Telecomunicações), discussões realizadas na ABERT (Associação Brasileira de Emissoras de Rádio e Televisão) e seguindo uma tendência mundial, espera-se num futuro próximo (entre 2008 e 2011) a introdução e a expansão da TV Digital no Brasil. Alguns especialistas consideram que a introdução desta tecnologia no país pode movimentar um mercado superior a R\$ 100 bilhões nos próximos 5 anos, considerando a gradual substituição da infra-estrutura atualmente disponível que contempla aproximadamente 1 bilhão de televisores no mundo, sendo que o Brasil possui da ordem de 54 milhões de televisores. Com a introdução gradativa da TV Digital (IPTV) em médio prazo (entre 2005 e 2010), espera-se uma verdadeira transformação do atual conceito conhecido de TV a partir da convergência intensa com a Internet avançada (fixa e móvel).

A informatização da população brasileira vem acontecendo de forma gradativa, na medida do possível, estão sendo implementados programas de incentivo à inclusão digital. Primeiro foi implantado o projeto "Computador para Todos", que segundo o governo, até o momento já foram vendidos mais de 500 mil PCs, e agora vem destacando um programa de incentivo a venda de laptops através de financiamentos com juros menores do que os adotados no varejo, com linhas de crédito oferecidas pela CEF, pelo Banco do Brasil e por varejistas credenciados pelo Banco Nacional de Desenvolvimento Econômico e Social (BNDES). Mais recentemente foram criados diversos telecentros/infocentros de inclusão digital.

Pesquisa realizada pelo INSTITUTO BRASILEIRO DE INFORMAÇÃO EM CIÊNCIA E TECNOLOGIA, o número de pontos, em milhares, de Inclusão Digital no Brasil cresceu de 12 no ano de 2005 para 16,7 no ano de 2006, mostrando assim que o Brasil está se inserindo cada vez mais no mundo digital. Os investimentos, para a popularização da informática, na área educacional têm aumentado cada vez mais. A criação da Fundação Um 
Laptop Por Criança (OLPC, na sigla em inglês) é a tentativa mais ambiciosa de equipar crianças pobres de países em desenvolvimento com computadores, e pode, segundo analistas, provocar o crescimento dessa indústria em mercados em desenvolvimento.

No Brasil trata-se de um produto extremamente inovador, no entanto nos países desenvolvidos esse tipo de tecnologia já vem sendo pensado a um bom tempo. A Apple, por exemplo, tem se interessado e colhido bastantes frutos no contexto educacional, visto que, ela disponibiliza descontos para governos locais, estaduais e federais em troca de parcerias e com isso consegue operar com convênios junto a escolas e universidades, comercializando seus produtos a preços mais baixos.

De acordo com a análise de alguns críticos da revista info exame, a exemplo, Sandra Carvalho. "Nós, brasileiros, estamos começando a sair da idade das trevas em tecnologia", visto que, o crescimento nas vendas de computadores pessoais dobraram nos últimos dois anos. Fazendo com que o povo brasileiro esteja mais preparado para enfrentar a batalha do dia-a-dia na internet, o divisor entre a cidadania e a exclusão neste século. Segundo a ANATEL e ABERT, entre as inovações esperadas destacamos a grande capacidade bidirecional de intercâmbio de dados multimídia; o relacionamento mais sensitivo, personalizado e intuitivo entre o usuário e a TV/Internet; a individualidade no acesso à informação; e a integração de multiserviços à TV/Internet como a automação doméstica, segurança, telejogos, teleducação, elemedicina, telecomércio, dentre outros.

A IPTV aos poucos vem sendo inserida no mercado, assim será possível analisar de forma mais concreta seus defeitos e restrições. Ela está no ar, pelo menos para 4 mil domicílios paulistanos da bastada região dos Jardins, que participam de um projeto piloto da Telefônica. A operadora testa ali sua nova rede de fibra óptica, com velocidade de 30 Mbps, bem maior do que a velocidade máxima, $8 \mathrm{Mbps}$, oferecida em outras áreas pela empresa. Um fator importante a ser ressaltado da IPTV é que diferentemente de "revoluções" passadas que não tiveram apoio das grandes indústrias, como exemplo, kazaa e Skype, o serviço de TV pela internet tem esse apoio devido aos seus altos padrões de propriedade intelectual, portabilidade, interatividade, publicidade e conteúdo. Segundo Dagomir Marquezi, crítico da revista info exame, "Eu já tive a oportunidade de conectar meu laptop a um monitor LCD de 42 polegadas. Se ainda tivesse alguma dúvida sobre a grande convergência, acabaria ali mesmo. A internet está transformando a TV num fenômeno completamente diferente do que conhecemos até agora. E fenômeno como o Joost e o Youtube, são esperanças para quem vive sob um governo obcecado com a palavra controle".

\section{SOLUÇÃO PROPOSTA}

Com base no que foi exposto no artigo e em estudos prévios a solução proposta é a criação de um ambiente de software de colaboração com a visualização avançada de conteúdos por meio da internet e da televisão digital para motivar e viabilizar a troca de conhecimentos entre alunos. Este ambiente deve permitir a geração de conteúdo desenvolvido pelos próprios alunos por meio de tecnologias multimídia de áudio e vídeo. A produção e uso desse conteúdo são acompanhados pelos professores ou alunos monitores por meio de funções específicas do sistema. Todo o progresso de cada aluno ao longo das atividades pode ser acompanhado, via TV Digital, pelos pais de cada um. Dessa forma, obtém-se uma infraestrutura tecnológica para suportar a integração alunos, pais e escola utilizando as tecnologias mais adequadas a cada um. O aprimoramento desse novo ambiente visa 
motivar a criação e troca de conhecimentos extra-sala de aula entre os alunos por meio de jogos, mundos virtuais e sistemas para a TV Digital. As vantagens são várias:

- No que diz respeito à TV digital e o acompanhamento dos alunos por um mecanismo de mais fácil acesso pelos pais podermos obter uma melhor interação entre pais e alunos e dando mais uma ferramenta para colaborar com prática, ainda muito limitada, da educação familiar.

“TV DIGITAL, não é só alta definição, é muito mais a capacidade de criar comunidades ao redor de programas e aplicações, com o público interferindo no correr dos acontecimentos da tela, o que muda para sempre a noção do que é televisão, desde a experiência de uso até o processo de concepção, produção e "operação" de emissoras e "canais". Além do sinal de vídeo, as emissoras passam a "emitir" software e têm que reagir à interação dos usuários com o mesmo, na maioria das vezes em tempo real." Silvio Meira [12].

- Em termos de motivar o aluno extra-sala de aula, prover um ambiente atrativo, com visualização avançada, permite motivar os alunos para a criação e a troca de conhecimentos entre eles. Além disto, este ambiente passa a ser um aliado do professor que irá incentivar seus alunos a realizarem atividades diferenciadas e inovadoras fora da sala de aula.

Em um futuro bem próximo os microcomputadores farão parte do cotidiano da grande maioria dos indivíduos. Confiante nessa análise a solução foca em mecanismos da IPTV. IPTV tem como estratégia quebrar as barreiras geográficas que a TV impõe, a novidade tem o objetivo de oferecer para os internautas bastante conteúdo e também comodidade. Possui um formato inteligente, fácil, de rápida navegação, a partir de vídeos, armazenados ou ao vivo, publicados em um serviço de IP, que podem ser acessados a qualquer momento pelo computador, e futuramente, por outros meios, como o celular. Trata-se de um grande mercado e com perspectivas reais de crescimento nos próximos anos e é justamente nele que pretendo atuar com uma nova solução. Por estas razões, tratar-se efetivamente de um produto bastante inovador que atenderá demandas reais do mercado de ensino a distância por meio de TV DIGITAL, via IPTV, levando em consideração a convergência digital e a interação dos usuários. A solução proposta tem foco no mercado de educação e diz respeito a cursos, treinamentos, capacitações e orientações em geral de: i) funcionários, colaboradores de organizações corporativas públicas e privadas; ii) alunos e professores da rede de ensino pública e privada; iii) projetos educacionais de inclusão social por parte de projetos de governo público e do terceiro setor; iv) re-qualificação profissional. Dentre as possibilidades de aplicações na área de educação à distância, abertas pela IPTV, e que serão estudadas e analisadas no contexto do projeto proposto podem ser citadas as seguintes:

\section{- Aulas:}

Aulas podem ser ministradas sem a presença física de um professor, estando o aluno presente em sua casa ou em uma escola. As aulas podem ser compostas por objetos multimídia previamente armazenados, os quais permitem ao aluno a navegação e interação de acordo com suas preferências. Caso o aluno tenha necessidade de sanar alguma dúvida em relação à aula, é possível que ele faça novas navegações no material sugerido, ou ainda tire suas dúvidas com um professor remoto e ao vivo, que pode se encontrar disponível como um serviço do sistema. Este serviço possibilita que o professor atenda remotamente 
uma quantidade grande de alunos. Na falta de um professor remoto ao vivo, o aluno pode deixar postadas questões de seu interesse.

\section{- Palestras e Discussões}

Palestras e discussões podem ser realizadas na forma de vídeo conferência possibilitando aos alunos debaterem um determinado assunto com especialistas na área ou com outros alunos. Estas palestras também podem ser utilizadas em forma de cursos de atualização dos professores e para troca de experiências.

\section{- Enciclopédias virtuais:}

Podem ser disponibilizadas para pesquisas uma infinidade de informações localizados em diversos pontos ue podem ser acessadas tanto por professores como por alunos a qualquer momento. Os dados multimídia, capazes de incluir informações de áudio, vídeo e imagem, permitem o enriquecimento das enciclopédias, que podem ainda trazer informações ao vivo,como o vídeo de um evento de interesse que esteja acontecendo no instante da consulta.

\section{- Jogos Educacionais}

Podem ser formados grupos de alunos para participarem de gincanas educacionais. Estas gincanas podem ser formadas por provas previamente existentes no sistema ou provas elaboradas por cada um dos grupos participantes. Todas estas provas podem ser acompanhadas por um professor que pode intervir e sugerir novas provas, lembrando que para a elaboração destas provas poderão ser utilizados os mais variados e complexos recursos multimídia visando aumentar o interesse dos participantes.

- Interação com a WWW

A TV-Interativa permite ainda a interligação com a WWW e, portanto, a disponibilização para seus usuários de todo o material e aplicações educativas produzidas para a WWW.

\section{CONCLUSÕES}

A TV Digital já é uma realidade. As possibilidades de entretenimento, aprendizado e interatividade disponibilizadas estão fazendo com que os provedores de serviços e também os provedores de conteúdo, cada vez mais, convirjam para um mesmo ponto: o usuário.

Com a utilização da tecnologia de TV Digital deverá criar um novo ferramental para disponibilização de ensino em larga escala gerando mais educação que precisa ser urgentemente massificada para inclusão definitiva dos países subdesenvolvidos. O andamento dos estudos sociais e tecnológicos, somado às articulações governamentais em torno da definição de um padrão para o Sistema Brasileiro de Televisão Digital, aponta um caminho sem volta em relação à transformação da televisão brasileira, principalmente enquanto possibilidade de inclusão social e uso educativo. Esse empenho é certamente o principal enfoque que parecem ter a intenção de agregar ao instrumento uma capacidade de aumento da inclusão digital para conseqüente diminuição das diferenças sociais no país, o que merece um estudo específico. 
Entretanto, para a concretização desses objetivos, os educadores e as instituições de ensino devem não somente acompanhar, mas alocarem-se como atores efetivos do processo decisório e interlocutores contundentes dos debates desenvolvidos. Partimos, nesta pesquisa, das informações existentes e expressas nos documentos sobre as reais possibilidades de aplicação dos novos recursos televisivos no contexto apenas informal dos processos educativos. Foram apresentadas algumas possibilidades potenciais de uso cultural e de acesso ao conhecimento da ferramenta, sem ainda abordar os usos didáticos específicos, estudo que deverá ainda ser desenvolvido. Mesmo assim, já se vislumbram uma possibilidade de apropriação positiva dos recursos pelas emissoras e potenciais provedores de conteúdos. A ampliação do número de canais com a possibilidade da ocupação desse espaço pelas emissoras comunitárias, educativas ou redes de intercâmbio de conteúdos educativos é uma oportunidade que não pode ser desconsiderada pelos interessados na promoção social deste país. A possibilidade da implantação destes serviços na comunidade envolvida retrata a caracterização de um papel ativo, contrário à passividade tradicional dos meios utilizados atualmente, gerando propostas que criem uma relação entre a TV digital e o telespectador ativo de caráter participativo e crítico, não só dentro da escola, como também fora dela.

Assim, estaremos oferecendo uma seqüência de atividades sistematizadas sobre o uso da TV Digital na comunidade escolar, de maneira que a educação audiovisual deixe de ser uma atividade esporádica no decorrer do ano letivo e se torne num dos objetivos educativos básicos do cotidiano escolar.

\section{REFERENCIAS}

[1] Sacrini, Marcelo. 2005. O uso da Televisão Digital no contexto educativo. ETD. Educação Temática Digital, Campinas, v.7, n.1, p.31-44. Julho 2005.

[2] Amaral, Sérgio F Moutinho, D. A TV Digital Interativa no espaço educacional. Jornal da Unicamp, Campinas, edição 229, de 15 a 21 s 2003.

[3] Santos, A. C. O.Governo Sociedade Civil e a (des)informação sobre a TV Digital no Brasil: O SBTVD, UNIrevista, vol $1 \mathrm{n}^{\mathrm{o}}$ 3: (julho 2006)

[4] Santos, A C O Reflexões sobre a convergência tecnológica: A TV digital interativa no Brasil, 'www.bocc.ubi.pt, 2003

[5] Barros, J.R.B.D; Silva, A.R.; Ferraz C. A.G.e Rosa, N.S. 2004. Projetando um Serviço de Descoberta de Canais para TV Digital.Faculdade Integrada do Recife, 2004.

[6] Fernandes, J. Lemos, G., Elias, G.. Introdução à TV Digital Interativa: Arquitetura, Protocolos, Padrões e Práticas. Anais da Jornada de Atualização em Informática do Congresso da Sociedade Brasileira de Computação, JAISBC, Salvador BA, Agosto de 2004. 
[7] Amaral, S. F. A TV Digital Interativa no Espaço Educacional. Jornal da Unicamp, set. de 2003. Disponível em: http://www.unicamp.br/unicamp/unicamp_hoje/ju/setembro 2003/ju229pg2b.html Consultado em: 15/10/2007

[8] Pato, L.M.C., IPTV: Será a Solução para a Difusão de iTV? Revistas Eletrônicas de Ciência da Comunicação Portal Revcom, 2007 - http://revcom.portcom.intercom.org.br, acessado em 15/10/2007

[9] Hira, C. Costa, L.C. Nunes, R.P. Real, L.C.V. e Zuffo, M.K. Sistema Operacional do Terminal de Acesso de Referência, Anais do XXVII Congresso da SBC, Julho de 2007

[10] Paes A, Antoniazzi R. Padrões de Middleware para TV Digital, UFF - Universidade Federal Fluminense - Centro Tecnológico Departamento de Engenharia de Telecomunicações, 2005.

[11] IBGE - PNAD - Pesquisa Nacional por Amostra de Domicílios, 2005.

[12] Meira, S - http://blog.meira.com , Junho de 2006: acessado em 19/10/2007

[13] CPqD. 2004. Centro de pesquisa e desenvolvimento em pesquisa e telecomunicações. Como o Modelo de TV DIGITAL brasileiro se insere no contexto de Pesquisa e Desenvolvimento no Brasil

[14] Asociación Televisión Educativa Iberoamericana. Canal Atei 24 horas. http://www.ateiamerica.com/TVIP/ , Julho de 2006, acessado em 19/10/2007 